\title{
A proteomics view on integrin-mediated adhesions
}

\author{
Aki Manninen ${ }^{1}$ and Markku Varjosalo ${ }^{2}$
}

\author{
${ }^{1}$ Aki Manninen (author for correspondence) \\ Adjunct Professor of Cell Biology \\ Biocenter Oulu, Oulu Center for Cell-Matrix Research \\ Faculty of Biochemistry and Molecular Medicine \\ University of Oulu \\ Aapistie 5, 90220, Oulu, Finland \\ Email: aki.manninen@oulu.fi \\ Tel.: +358-(0)294 486081 \\ Fax: $+358-8-5376115$ \\ ${ }^{2}$ Markku Varjosalo \\ Institute of Biotechnology \\ Biocenter 3 \\ University of Helsinki \\ Viikinkaari 1, 00790, Helsinki, Finland \\ markku.varjosalo@helsinki.fi
}

Abbreviations: DPDPB - 1,4-Bis[3-(2-pyridyldithio)propionamido]butane, DSP - dithiobis(succinimidylpropionate), DTBP - dimethyl 3,3'-dithiobispropionimidate, DTSSP - 3,3'dithiobis(sulfosuccinimidylpropionate), ECM - the extracellular matrix, ERK2 - extracellularregulated kinase 2, FA - focal adhesion, FN - fibronectin, IAC - integrin adhesion complex, IQSEC1 IQ motif and SEC7 domain-containing protein 1, MAP4K4 - mitogen-activated kinase kinase kinase kinase 4, MEK1 - mitogen-activated kinase/ERK kinase 1, MT - microtubule, VCAM-1 - Vascular cell adhesion protein 1

Keywords: Adhesome, focal adhesion, integrins, mechanotransduction Total number of words: 8982 


\section{Contents}

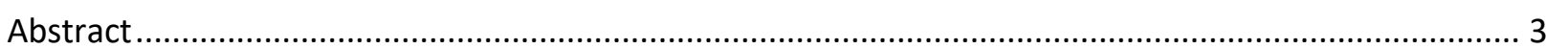

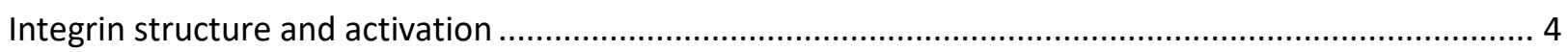

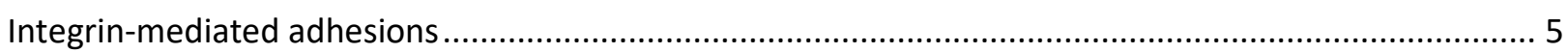

Composition of the integrin adhesome - ever increasing complexity? ............................................. 6

Isolation of integrin associated complexes for proteomics ........................................................... 7

Lessons learned from proteomic analysis of integrin associated complexes......................................... 9

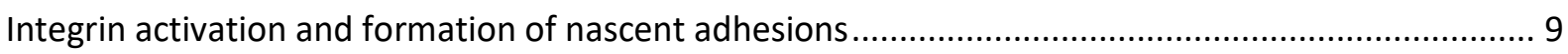

Force-dependent maturation of nascent adhesions and disassembly of focal adhesions ................... 10

Organization of protein complexes at focal adhesions ............................................................. 13

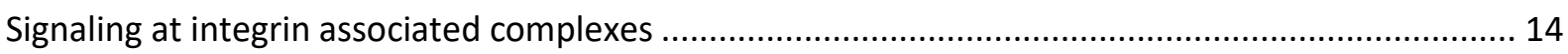

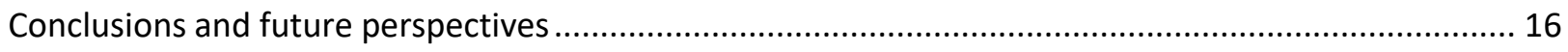

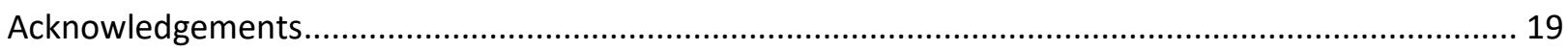

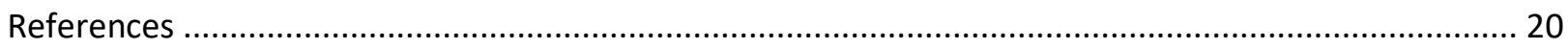

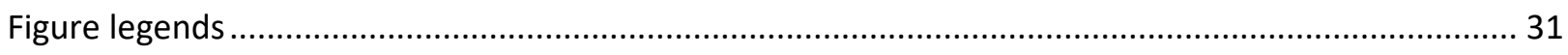




\section{Abstract}

Individual cells in multicellular organisms constantly explore their microenvironment, or niche, to obtain spatial information that is used to regulate cell behavior to maintain tissue integrity. The extracellular matrix (ECM) is an important source of such spatial information. Binding of the integrin family receptors to the ECM triggers formation of integrin adhesion complexes (IACs) which link the ECM network to cellular cytoskeleton via remarkably large multiprotein complexes collectively referred to as the integrin adhesome. Recent advances in proteomics have enabled researchers to study the IAC composition in detail. Various biochemical IAC isolation methods and culture conditions have been employed to study the composition and dynamics of integrin-mediated adhesions mainly in fibroblasts and lymphoblasts. These studies have led to identification of daunting lists of potential IAC components. This review focuses on the current status of proteomicsdriven research seeking to understand integrin functions by comprehensive analysis of IAC components. These systems level approaches have revealed the complexity of biochemical and biomechanical signals that are processed at IACs and provide a novel insight into how these signals are conveyed to regulate cellular behavior. 


\section{Integrin structure and activation}

Integrins constitute a large family of $\alpha \beta$-heterodimeric receptors which emerged during evolution to regulate multicellular organization and communication between the different cell types in the early metazoans [1]. In vivo, integrins orchestrate cell-ECM and cell-cell interactions that are critical for cell adhesion, polarity and migration and thereby formation and maintenance of most if not all multicellular tissues as well as many processes involving regulated cell adhesion such as leukocyte activation [2]. In mammals, $18 \alpha$-subunits and $8 \beta$-subunits can reportedly form 24 distinct heterodimers [3]. In evolutionary terms integrins fall roughly into four groups; RGD-, laminin- and collagen-binding integrins and leukocyte integrins the latter two containing an additional $\alpha$ l-domain that is not present in the first two groups [1]. Some integrin subunits, such as $\beta 1, \beta 2$ and $\alpha \mathrm{V}$, can pair with multiple other subunits while most subunits form only 1 or 2 different heterodimers [3]. Most cell types express several different integrin subunits. Importantly, although there is significant overlap in the ligand-binding specificity between the different integrins their functional redundancy is only partial as evidenced by the documented phenotypes of integrin-knockout mice [4]. It is obvious that cellular context, cell type(s) involved and the surrounding ECM microenvironment, modulate integrin-mediated responses but the molecular mechanisms explaining the signaling specificity of the different integrin heterodimers remain poorly understood.

Integrins are type I transmembrane glycoproteins with a large extracellular domain and a short intracellular tail [5]. Integrin activation involves complex conformational changes that are regulated by effectors binding mainly to the integrin cytoplasmic tails which contain several motifs that have been reported to interact with numerous binding partners [5-9] (Figure 1A). Accordingly, most of the canonical adhesome proteins are cytoplasmic or intracellular peripheral membrane proteins [10]. The key property of activated integrins is to form a link between the ECM and cellular actin

cytoskeleton [11]. Due to the dynamic nature of cell-ECM interactions, the formation and 
maintenance of such links need to be highly regulated. Inside-out activation of integrins is triggered when cytoplasmic integrin activating proteins, talin and kindlin in particular, bind to the C-terminal tail [12]. Outside-in activation is triggered after integrin first engages with its ECM ligand thereby facilitating subsequent recruitment of cytoplasmic activators such as talin and/or kindlin to the Cterminal integrin tails [13-17]. Both talin and kindlin can serve as a linker connecting integrins to actin filaments $[18,19]$. Other proteins reportedly linking integrin cytoplasmic domains to actin are $\alpha$-actinin [20], filamin [21], tensin [22], myosin-X [23] and ILK/Pinch/Parvin-complex [24-28]. These proteins are thus central adhesome components and with the exception of myosin- $X$, all of them are found in most proteomic studies on integrin adhesions complexes (IACs) [29].

\section{Integrin-mediated adhesions}

Focal adhesions (FAs) are prototypical integrin-mediated cell-ECM contact sites that link cellular actin cytoskeleton to the ECM scaffold [30]. Nascent adhesions or focal contacts are initially formed by one or few integrins that progressively cluster to form FAs (Figure 1B) [31, 32]. FAs can be several square micrometers in size and they serve as anchoring points for actin stress fibers which also exert strain on the FAs they are linked to. These integrin-associated actin-rich platforms define the bonafide "adhesome" as they gradually assemble up to hundreds of different proteins components [2] (Figure 1C). Individual components or smaller units of FAs, including integrins themselves, undergo dynamic diffusion to and from the FA [33]. On one hand, FAs need to be actively maintained in order to prevent their disassembly. On the other hand, FAs serve as environmental probes by continuously assembling and disassembling in a regulated manner. Cell locomotion, stress fiber dynamics and/or retrograde actin flow eventually drive formation of more ventrally positioned fibrillar adhesions (FBs) which appear to be connected to less contractile (or non-contractile) actin filaments when compared with FAs [34]. Whether talin-enriched FAs mature into tensin and $\alpha 5 \beta 1$-integrin enriched 
FBs or if they rather represent two different types of integrin-mediated adhesions can be debated but they do contain different sets of effectors $[30,34]$. Recently tensin-rich FBs were identified as hot spots for $\alpha 5 \beta 1$-integrin internalization and were proposed to be specifically linked to energy metabolism [35]. FAs can be formed by different integrin heterodimers and $\beta 1$ - and $\alpha \mathrm{V}$-integrins appear to synergistically drive FA maturation [36, 37]

FAs are not the only type of integrin-mediated adhesive structures. Pseudopodia, podosomes and invadopodia are integrin-dependent adhesive structures that have been functionally linked to ECM degradation [38]. Proteomic analyses of these structures have been performed and while they share several components with FAs there are also significant differences reflecting their specialized functions [39-43]. In the following chapters I will, however, focus on the FA-associated adhesome that has been characterized in multiple studies.

\section{Composition of the integrin adhesome - ever increasing complexity?}

The composition of integrin associated complexes (IACS) is dynamically changing over time and space as it is assembled in response to mechanical stress and disassembled via endocytic and/or proteolytic processes [44-50]. The literature-curated integrin adhesome consisting of 90 core components and 66 peripheral components was originally defined by combining data from individual focused protein-protein interaction and microscopy-based studies, as well as functional genomics approaches $[2,10,51]$. More recently due to emergence of unbiased IAC proteome analyses the number of IAC components has expanded from 200 up to more than 2400 proteins $[29,52]$. Comparative proteomic analyses revealed that most of these so-called meta-adhesome proteins are cell and/or context-specific as significant differences were observed between the IACS analyzed from different cell lines [29]. Differences were also found depending on which specific 
integrin is forming the adhesion or whether nascent or more mature adhesions were isolated [29, 53-57]. Despite the observed high variability of IAC associated proteins, a core consensus adhesome consisting of 60 proteins which were consistently identified from the different IAC preparations was proposed [29]. Interestingly, only half of the proteomics-derived core consensus adhesome proteins overlapped with the literature-curated adhesome (Figure 2A). Along the same lines, there is surprisingly little overlap with adhesome components identified from different types of proteomic analyses although they do generally fall within similar functional groups (Figure 2B-D).

\section{Isolation of integrin associated complexes for proteomics}

The most critical step in proteomics of IACs is sample preparation. Selection of the isolation method is not trivial because integrin-mediated adhesion complexes are dynamic, their formation and disassembly are mechanosensitive such that they respond to forces by changing their composition. In most approaches cell culture plates have been coated with an integrin ligand, commonly fibronectin (FN), but substrate-coated paramagnetic beads have also been used, particularly for suspension cells $[29,53,58]$ (Figure 3A). Importantly, FAs do not undergo mechanical maturation when substrate-coated beads are used, thus this approach is useful when focusing the analysis on nascent adhesions [29]. Integrin heterodimer repertoire adds another layer of complexity because most cell types express multiple different integrin heterodimers. Furthermore, many of the interactions within IACs are relatively weak and/or transient and therefore mild and rapid isolation procedures are needed $[54,59,60]$ (Figure 3B). One solution to this challenge relies on the use of chemical crosslinkers (eg. DTBP, DTSSP or DSP/DPDPB) in order to stabilize and preserve low affinity interactions [55-58, 61, 62] (Figure 3C).

Regardless of the method, biochemical isolations and/fractionations will always contain some impurities. When combined with the sensitive state-of-art mass-spectrometry (MS) analyses, these 
impurities (eg. unspecific binders) together with abundant proteins typically found as contaminants in proteomic analyses pose a challenge how to separate real IAC components from a large number of non-specific contaminants. In some circumstances most frequent false positives on IACs can be excluded by utilizing a negative control ligand such as poly-L-lysine or transferrin onto which cells bind in an integrin-independent manner $[53,56,57,62]$. However, the selection of negative control is not a trivial issue as different negative controls can have different set of non-specific hits [63]. Moreover, some of the established key adhesome components are found with medium-to-high frequency in contaminant repositories such as "CRAPome" [64]. Vascular cell adhesion protein 1 (VCAM-1) mutant, VCAM-1 D40A that has lost its ability to interact with $\alpha 4 \beta 1$-integrin, is one elegant example of carefully selected negative control that differentiates VCAM-1-bound $\alpha 4 \beta 1$ integrin associated complexes from integrin-independent and non-specific contaminants [58].

IACs reside at membranes and likely contain many transmembrane and membrane-associated proteins whose interactions with integrins could depend on intact membranes. Use of detergents to solubilize membrane proteins and at the same time preserve large yet delicate membraneassociated protein complexes can be a difficult task that needs to be carefully optimized $[65,66]$. Some receptor complexes, such as the TCR-complex have been successfully immuno-isolated without detergents or chemical crosslinkers by coupling paramagnetic bead approach with nitrogen cavitation resulting in membrane vesiculation [67]. In our hands, however, this approach has been difficult to systematically reproduce for IACs (Manninen et al. unpublished). Moreover, bead-based approaches are limited to obtaining nascent adhesions. Another interesting technology is the BiolD method that utilizes promiscuous biotin ligase that can be fused to protein of interest to biotinylate its proximal interacting proteins in vivo [68]. This is a powerful novel approach that is perfectly suited for capturing transient and/or weak protein-protein interactions. BiolD-technology has been 
recently used to characterize the interaction partners of two central FA proteins, paxillin and kindlin2 [69] (Figure 3D). BiolD analysis revealed a much more restricted set of IAC components when compared with mechanical isolation of IACs and together with standard affinity-purification approaches provides an interesting additional method that can be utilized to dissect subsets of IACS $[56,69,70]$.

\section{Lessons learned from proteomic analysis of integrin associated complexes}

\section{Integrin activation and formation of nascent adhesions}

Most of the current proteomics studies have been designed to capture active integrin complexes. However, integrin inactivation is not a default state but is also regulated. Therefore inactive integrins form also complexes with many proteins [4]. Byron and colleagues addressed this issue by utilizing conformation-specific integrin antibodies to capture either active or inactive IACs using the bead-based method (Figure 3A) [71]. Fibroblasts spread efficiently on substrates coated with immobilized activating or inhibitory integrin-antibodies but they formed stress fibers only when spreading on activating integrin antibodies. Somewhat surprisingly, the majority (64\%) of the 2265 proteins identified by MS analysis were associated with both active and inactive IACs [71]. Active IACs were found to be enriched with actin-binding proteins and a number of microtubule (MT) interacting proteins such as MT plus end tracking (+TIPs) proteins. This is in agreement with previous findings where MTs were found to target FAs resulting in stabilization of peripheral MT localization $[72,73]$. By using immobilized activating or inhibitory integrin antibodies Byron and colleagues showed that MTs were stabilized only at active integrin adhesions. What is the role of MT stabilization at forming FAs? MTs are not required for FA assembly or maturation. In contrast, MTs are involved in FA disassembly and inhibition of MT oligomerization enhances FA maturation 
$[50,72] . M T$ targeting to integrin-mediated adhesions might direct specific membrane cargo to form polarized domains required for example oriented cell division or cell polarization [74-76].

As mentioned above integrin activation involves large conformational changes [7]. It has been proposed that proximal integrin effectors interact preferentially with either active or inactive conformation thereby promoting integrin activation or inhibition, respectively $[8,77]$. In many cases the different proteins have been suggested to compete for binding to integrins by interacting with the same or an adjacent motif and thereby favor a certain conformational state of integrin [9]. Thus, a significant number of proteins directly interacting with integrins should interact in mutually exclusive manner. Curiously, well-characterized proteins shown to inhibit integrin activation were not significantly enriched in inactive IACs [4]. This could reflect differences in the regulation of different integrin heterodimers. Alternatively, inhibitory integrin-associated proteins such as sharpin or integrin cytoplasmic domain-associated protein-1 (ICAP-1) might only function upon particular signals that are not triggered when integrins are rendered inactive by conformation specific antibodies. It is also noteworthy that IACs in this study were captured by using paramagnetic beads and thus proteomic analysis focused on nascent adhesions in the absence of force-dependent maturation of IACs. However, inactive IACs were found to be enriched in Rho and Ras GTPase family members that are involved in cytoskeletal organization and membrane trafficking. While these effectors are known regulators of FA dynamics the possible mechanisms how they associate with inactive integrins and/or their potential functions to inactivate integrins await further studies.

\section{Force-dependent maturation of nascent adhesions and disassembly of focal adhesions}

When activated integrins connect to both actin and sufficiently rigid ECM they have been shown to display catch bond behavior leading to more stable integrin-ECM interaction and clustering of 
integrins at FAs [78]. Catch bonds have the ability to strengthen their affinity to the ligand when force is exerted on the interacting molecules [79]. These forces are initially generated by retrograde actin flow at lamellipodia and upon further maturation of the adhesions by RhoA/RhoA-associated kinase (ROCK)-driven actomyosin contractility [44, 80, 81]. Inhibition of myosin function causes FAdisassembly. Curiously, proteomic studies identified many Lin11/ Isi-1/Mec-3 (LIM)-domain containing proteins which were highly enriched in IACs in actomyosin-contractility dependent manner [54,57]. Several LIM domain proteins shuttle between nucleus and cytoplasm and/or associate with actin cytoskeleton [82]. Many LIM-domain proteins contain more two or more LIMdomains each of which consists of two tandem zinc-fingers [82]. Such structure makes LIM-domain arrays suitable for stretch sensing at actin filaments as has been reported for zyxin and muscle LIM protein $[83,84]$. Although mechanistic details remain unresolved, force-dependent recruitment of multiple LIM-domain proteins to FAs possibly reflects their general importance in mechanoresponsive integrin signaling and stress fiber formation [31, 32]. Alternatively, increased number of LIM-domain proteins could be merely due to higher concentration of filamentous actin accumulating at mature FAs. Some of the key hubs (paxillin, pinch, zyxin) at FA contain LIM-domains. Mechanosensitive LIM-domain-mediated strengthening of the actin filament connections could establish a tension-dependent feedback loop that adjusts actin network organization in response to mechanical stress thereby maintaining mechanical homeostasis. Actin-associated proteins in general are abundant in IACs. On a cautionary note, actin forms large insoluble networks that span the length of a cell and thus many actin-binding proteins including LIM-domain proteins might be indirectly retained within the IAC associated interconnected actin polymers, particularly when chemical crosslinkers are used. 
FA-associated MTs likely serve as tracks to target trafficking of various membrane cargo to cellECM adhesions but they are also involved in FA disassembly [85]. Disruption of the MT network with nocodazole leads to increased RhoA-mediated myosin contractility and thereby formation of stress fibers and FA maturation to FBs $[86,87]$. MTs associate with a Rho guanine nucleotide exchange factor 2 (GEF-H1) that is released upon nocodazole-mediated disruption of MTs [88]. GEF-H1-driven activation of RhoA and subsequent stimulation of myosin-mediated contractility promotes FA maturation. One of the prominent cellular functions of integrin-mediated adhesions is their role as mechanosensors $[32,89]$. In order to respond to mechanical stimulus integrin-mediated adhesions need to be able to adjust their composition according to mechanical properties of the ECM. Nocodazole-driven FA disassembly implicates the regulation of MT network as an important component of mechanotransduction machinery. Interestingly, Fässler and colleagues identified GEF-H1 as a component of $\alpha \mathrm{V}$-integrin associated IACs and a critical effector regulating substrate stiffness-induced myosin reinforcement [56]. Both $\alpha \mathrm{V}$ - and $\beta 1$-integrins can alone form nascent adhesions and mediate cell attachment. However, several studies support cooperative functions for $\alpha \mathrm{V}$ - and $\beta 1$-integrins at FAs to enable mechanoresponsive signaling and modulation of the composition of FAs $[36,56,90,91]$. It is tempting to speculate that $\alpha \mathrm{V}$-integrins contribute to FA assembly by recruiting GEF-H1 (or MTs) whose release or activation is then somehow regulated by MT dynamics. Proteomic analysis of IACs in fibroblasts identified a number of proteins that have been previously implicated in tethering MTs to peripheral membranes [55]. At least some of these proteins, however, were enriched at IACs in nocodazole-treated cells suggesting that their abundance is negatively regulated by intact MT network. Whether these proteins recruit MTs at focal adhesions and are then released or if they function to actively trigger MT-dependent FA disassembly remains unclear. Another study purified IACs from keratinocytes and identified a MT +TIP-associated end-binding 2 (EB2)/MAP4K4/IQSEC1-complex that was shown to actively mediate 
FA disassembly [60]. In light of these findings it is clear that MT and actin networks converge at FAs where complex interactions regulate the stability of each network. Nevertheless, further studies are needed to clarify how this interplay is regulated.

\section{Organization of protein complexes at focal adhesions}

Despite the large number and confusing heterogeneity of IAC components localizing to FAs, structurally FAs are highly organized. Super-resolution microscopy revealed that integrin cytoplasmic tails and proteins intimately associating with them such as focal adhesion kinase (FAK) and paxillin, form a membrane proximal integrin signaling layer (within $\sim 20 \mathrm{~nm}$ of the plasma membrane) that is juxtapositioned with so-called mechanotransduction layer containing the mechanoresponsive molecules talin and vinculin linking adhesions to the actin network [92]. While actin was observed throughout the different layers high amounts of actin together with various actin binding proteins constitute the actin regulatory layer blanketing the mechanotransduction layer. Protein-protein interaction analysis of the core consensus adhesome identified four central hubs coordinated by 1) talin and vinculin 2) FAK and paxillin 3) ILK/Pinch/Parvin (IPP) and kindlin and 4) $\alpha$-actinin, zyxin and vasodilator-stimulated phosphoprotein (VASP) [29]. These hubs can be positioned to the above-mentioned layers with FAK/paxillin- and IPP/kindlin-complexes at the plasma membrane extending to mechanotransduction layer, talin/vinculin-network mostly within the mechanotransduction layer but spanning all the layers and $\alpha$-actinin/zyxin/VASP-complex concentrated at the actin regulatory layer [92]. Some experimental evidence for such layering was also provided by proximity biotin ligation approach where BirA fused to kindlin or paxillin preferentially labeled membrane-proximal components of FAs [69]. However, in contrast to superresolution microscopy, BiolD data suggested that FAK is positioned further away from the plasma membrane $[69,92]$. Additional studies are clearly required to resolve the spatial organization of the 
key FA components. Importantly, different integrin heterodimers show spatial segregation and/or different kinetics also in the plane of the membrane $[33,93]$.

The daunting complexity of IACs raises a question how the highly organized assembly is achieved. One possible explanation comes from a study by Horton et al. who performed a proteomic analyses on IACs in the absence or presence of an inhibitor for FAK that is a tyrosine kinase centrally involved in regulation of focal adhesion dynamics $[94,95]$. Somewhat surprisingly, FAK inhibitor had only minor effects on IAC composition despite significant decrease in the phosphotyrosine content at FAs [95]. In line with the proteomic data cell adhesion was also only minimally affected by FAK inhibition. In contrast, cell migration and proliferation were sensitive to FAK inhibition. Similar results were observed when Src, another FA-associated tyrosine kinase, was inhibited or even when the activity of both FAK and Src was blocked. An analysis of the dynamics of selected FA proteins revealed that the turnover rate and mobile fraction of phosphotyrosine-binding proteins were increased upon FAK and/or Src-inhibition [95]. These findings suggest that many of the protein complexes could pre-exist at IACS or in their proximity and the dynamics of their association within IACs is regulated by phosphorylation. Pre-assembled complexes are common in cellular signaling pathways [96]. In line with such model, the IPP complex consisting of ILK, pinch and parvin preassembles in the cytoplasm before it is targeted to FAs [97]. A dynamic pre-organized platform that is stabilized upon a general signal such as tyrosine phosphorylation would explain how highly organized IACs could rapidly assemble or disassemble to regulate cellular functions.

\section{Signaling at integrin associated complexes}

Integrin mediated focal adhesions are important not only structurally but also serve as cellular signaling platforms conveying signals from the ECM into cells and vice versa. Serine-, threonine- and tyrosine phosphorylation is the best studied post-translational modification involved in mediating 
cellular signals [98]. Several kinases and phosphatases have been implicated in the regulation of integrin-mediated signaling [99-101]. Phosphoproteomic analyses recapitulate these findings and show marked changes in protein phosphorylation upon cell adhesion $[56,62,102]$. These include the majority of adhesome proteins, particularly the group of adaptor proteins [62]. Although phosphorylation chains propagate the signal in cells phosphorylation of a particular protein is a spatially restricted event. Therefore, the phosphoproteome in isolated adhesions is different from total cellular phosphoproteome. Robertson et al. detected a number of phosphorylation events that were only observed in IACs demonstrating that these phosphorylation sites were modified only in active adhesions [62]. This finding is in agreement with the role of FAK/Src-mediated phosphorylation of IAC components specifically at FAs to stabilize their recruitment [95]. IAC phosphoproteome contained hundreds of proteins that were not detected in IAC proteome [62]. Importantly, it was noted that 19 of the 315 IAC components only found in the phosphoproteome are included in the literature-curated adhesome.

Phosphorylation-based signals are typically propagated along a chain of kinases and their corresponding substrates. Thus, all signaling proteins critical for FA formation or FA-mediated signal transduction are not enriched at IACs. Analysis of the total phosphoproteome in different conditions has also revealed novel regulators of $F A s[56,102]$. Schiller and colleagues detected more than one thousand differentially phosphorylated sites in 150 proteins when fibroblasts were seeded onto FNcoated substrate [56]. The analysis was performed in cells expressing $\alpha \mathrm{V}$-integrins or $\beta 1$-integrins alone or in combination. Activation of MEK1/ERK2- and the RhoA/ROCK/myosin-pathways were found to be preferentially driven by $\beta 1$-integrins whereas $\alpha \mathrm{V}$-integrins stimulated RhoA activity that was uncoupled from ROCK. Another study reported a phosphoproteomic time series analysis of HeLa cells adhering to type I collagen where 517 differentially phosphorylated residues in 357 
proteins were detected [102]. Out of these 357 candidate proteins, altogether 33 kinases or phosphatases were screened by RNAi. A series of cell biological assays identified DBF4, GRK6 and PAK2 as critical regulatory kinases orchestrating integrin-mediated cell adhesion and migration. FA mediated signaling is clearly context-dependent but by accumulating more studies in different cell types it will eventually be possible to delineate common integrin-proximal signaling modules that directly regulate FA dynamics. Despite the above-mentioned difficulties to draw generalizations, integrins are known regulators of growth factor receptor-mediated signaling and cell adhesion is commonly a prerequisite for growth factor receptor signaling and cell survival [103-105]. It is clear that several different mechanisms are employed in integrin/growth factor receptor crosstalk and a number of IAC components are also intimately linked to growth factor receptor signaling. Curiously, only few growth factor receptors are found in IACs [29]. Combination of proteomic analyses and genetic models will likely be helpful to unravel the complexity of integrin-growth factor receptor interplay.

\section{Conclusions and future perspectives}

The emerging complexity of integrin-mediated cell adhesions during the last few decades led to definition of the integrin adhesome, consisting of more than 200 proteins which either localize to FAs or interact directly with another adhesome protein or whose depletion clearly interferes with cell adhesion. More recently this literature-curated adhesome has been dwarfed by proteomic analyses of integrin-mediated adhesions that have increased the number of potential integrinassociated proteins to several thousands (Table I). Intriguingly, although a core consensus adhesome has been extracted that consists of 60 proteins most consistently identified in different proteomic studies, only half of them are found in the literature-curated adhesome [29]. Curiously, many of the literature-based adhesome protein absent from the IAC proteomes are kinases and 
other signaling proteins that may associate with adhesion complexes only transiently and via multiple weak interactions that might be disrupted during IAC isolation. What are then all these other proteins enriched at IACs (Figure 4)? Whether the IAC-enriched proteins groups that regulate RNA processing or translation reflect a yet uncharacterized machinery that links FAs to regulation of RNA biogenesis and protein synthesis is an interesting question for future studies $[106,107]$.

While the number of components in IAC proteomes from different cells and/or conditions is roughly similar a surprisingly small fraction of them is shared between the studies. This heterogeneity is even more surprising given that most of the proteomes come from few cell types and mainly focus on only few different ligands. It can be anticipated that once more proteomic studies on IACs from different cell types and substrates accumulate the meta-adhesome becomes even more heterogeneous. For example, epithelial cells that have so far obtained limited attention in proteomics studies express many different integrin heterodimer and efficiently adhere to FN, collagen and laminin. The crucial substrate for epithelial cells in vivo is laminin that is recognized by multiple different integrin and non-integrin receptors [108-110]. In addition to FAs formed by $\beta 1$ and $\alpha \mathrm{V}$-integrins, $\alpha 6 \beta 4$-integrins form hemidesmosomes in epithelial cells. Two distinct types of hemidesmosomes have been described, type I hemidesmosomes that are typical for keratinocytes and other stratified epithelial cells and type II hemidesmosomes that are found in simple epithelium $[111,112]$. The fundamental difference that distinguishes hemidesmosomes from focal adhesions is that they link to intermediate filament network via plectins and $\beta 4$-integrins [113]. Given the central role of actin dynamics and the abundance of actin-associated proteins in the FA adhesome, the proteome of hemidesmosomes will likely look quite different despite the interesting notion that the assembly of hemidesmosomes and FAs seem to be closely coordinated [114, 115]. Nevertheless, the complexity should not discourage proteomic approaches. On the contrary, comprehensive 
proteomic characterization of IACs combined with bioinformatics analyses of IACs proteomes and phosphoproteomes have already been successfully utilized to identify crucial protein modules and to predict important signaling modules regulating FA dynamics. Obviously, characterization of an extensive list of IAC proteins is not enough. Careful planning and design to select the most appropriate experimental conditions for comparative IAC analyses is of critical importance. Adhesion complexes, like any other cellular protein complexes, are likely build from modular units [116]. Quantitative MS analyses focusing on selected key IAC proteins will be necessary to resolve the stoichiometric composition of such modular units that assemble large integrin-associated complexes [117, 118]. A number of generic affinity purification MS approaches have been developed to study protein complexes at a proteome/systems level. These methods rely on high affinity epitope tags that are fused to the proteins of interests for single step or tandem affinity purification to increase specificity and yields in protein complex purification [119-121]. Systematic tagging of proteins along with improved sensitivity of MS-instrumentation enables rapid and reliable identification of copurifying proteins from relatively small amount of cells by current affinity purification MS workflows $[122,123]$. Proteomic results need to be validated by biochemical and cell biological analyses. In many cases specific depletion of selected IAC components will be necessary to dissect the different molecular networks when multiple receptors share a common ligand [56]. Comparison of the composition of related but functionally different types of integrinassociated adhesions such as podosomes and invadosomes will provide interesting insight into how the formation of these different adhesive structures is regulated [39-41].

Proteomic studies on cellular adhesions do face significant challenges when it comes to sample preparation. Isolation of subdomains from a joint network of two largely insoluble and highly interconnected scaffolds (the ECM network and cellular actin cytoskeleton) is not without problems. 
While the issues with IAC isolation are likely difficult to resolve alternative approaches such as BirAbased proximity biotin ligation can be used to complement the IAC analyses and alleviate the potential weaknesses of biochemical IAC isolation $[69,124]$. Comprehensive proteomic analysis of cellular functional units, such as FA, represents modern cell biology that will eventually expand our understanding of how cells function as a system. The current progress driven by relatively few research groups has paved the way and invites new researchers to tackle the challenge where joint efforts will be necessary to tackle the complexity of cell adhesion.

\section{Acknowledgements}

This work was funded by Academy of Finland (AM: 140974, 263770, 135560 and MV: 288475). 


\section{References}

[1] Johnson, M. S., Lu, N., Denessiouk, K., Heino, J., Gullberg, D., Integrins during evolution: evolutionary trees and model organisms. Biochim. Biophys. Acta 2009, 1788, 779-789.

[2] Winograd-Katz, S. E., Fassler, R., Geiger, B., Legate, K. R., The integrin adhesome: from genes and proteins to human disease. Nat. Rev. Mol. Cell Biol. 2014, 15, 273-288.

[3] Hynes, R. O., Integrins: bidirectional, allosteric signaling machines. Cell 2002, 110, 673-687.

[4] Bouvard, D., Pouwels, J., De Franceschi, N., Ivaska, J., Integrin inactivators: balancing cellular functions in vitro and in vivo. Nat. Rev. Mol. Cell Biol. 2013, 14, 432-444.

[5] Campbell, I. D., Humphries, M. J., Integrin structure, activation, and interactions. Cold Spring Harb Perspect. Biol. 2011, 3, 10.1101/cshperspect.a004994.

[6] Shattil, S. J., Kim, C., Ginsberg, M. H., The final steps of integrin activation: the end game. Nat. Rev. Mol. Cell Biol. 2010, 11, 288-300.

[7] Luo, B. H., Carman, C. V., Springer, T. A., Structural basis of integrin regulation and signaling. Annu. Rev. Immunol. 2007, 25, 619-647.

[8] Pouwels, J., Nevo, J., Pellinen, T., Ylanne, J., Ivaska, J., Negative regulators of integrin activity. J. Cell. Sci. $2012,125,3271-3280$.

[9] Legate, K. R., Fassler, R., Mechanisms that regulate adaptor binding to beta-integrin cytoplasmic tails. J. Cell. Sci. 2009, 122, 187-198.

[10] Zaidel-Bar, R., Itzkovitz, S., Ma'ayan, A., lyengar, R., Geiger, B., Functional atlas of the integrin adhesome. Nat. Cell Biol. 2007, 9, 858-867.

[11] Tamkun, J. W., DeSimone, D. W., Fonda, D., Patel, R. S. et al., Structure of integrin, a glycoprotein involved in the transmembrane linkage between fibronectin and actin. Cell 1986, 46, 271-282.

[12] Calderwood, D. A., Campbell, I. D., Critchley, D. R., Talins and kindlins: partners in integrin-mediated adhesion. Nat. Rev. Mol. Cell Biol. 2013, 14, 503-517.

[13] Lawson, C., Lim, S. T., Uryu, S., Chen, X. L. et al., FAK promotes recruitment of talin to nascent adhesions to control cell motility. J. Cell Biol. 2012, 196, 223-232. 
[14] Zhang, X., Jiang, G., Cai, Y., Monkley, S. J. et al., Talin depletion reveals independence of initial cell spreading from integrin activation and traction. Nat. Cell Biol. 2008, 10, 1062-1068.

[15] Wang, P., Ballestrem, C., Streuli, C. H., The C terminus of talin links integrins to cell cycle progression. J. Cell Biol. 2011, 195, 499-513.

[16] Takagi, J., Petre, B. M., Walz, T., Springer, T. A., Global conformational rearrangements in integrin extracellular domains in outside-in and inside-out signaling. Cell 2002, 110, 599-511.

[17] Beglova, N., Blacklow, S. C., Takagi, J., Springer, T. A., Cysteine-rich module structure reveals a fulcrum for integrin rearrangement upon activation. Nat. Struct. Biol. 2002, 9, 282-287.

[18] Jiang, G., Giannone, G., Critchley, D. R., Fukumoto, E., Sheetz, M. P., Two-piconewton slip bond between fibronectin and the cytoskeleton depends on talin. Nature 2003, 424, 334-337.

[19] Bledzka, K., Bialkowska, K., Sossey-Alaoui, K., Vaynberg, J. et al., Kindlin-2 directly binds actin and regulates integrin outside-in signaling. J. Cell Biol. 2016, 213, 97-108.

[20] Roca-Cusachs, P., del Rio, A., Puklin-Faucher, E., Gauthier, N. C. et al., Integrin-dependent force transmission to the extracellular matrix by alpha-actinin triggers adhesion maturation. Proc. Natl. Acad. Sci. U. S. A. 2013, 110, E1361-1370.

[21] Ehrlicher, A. J., Nakamura, F., Hartwig, J. H., Weitz, D. A., Stossel, T. P., Mechanical strain in actin networks regulates FilGAP and integrin binding to filamin A. Nature 2011, 478, 260-263.

[22] McCleverty, C. J., Lin, D. C., Liddington, R. C., Structure of the PTB domain of tensin1 and a model for its recruitment to fibrillar adhesions. Protein Sci. 2007, 16, 1223-1229.

[23] Zhang, H., Berg, J. S., Li, Z., Wang, Y. et al., Myosin-X provides a motor-based link between integrins and the cytoskeleton. Nat. Cell Biol. 2004, 6, 523-531.

[24] Yamaji, S., Suzuki, A., Sugiyama, Y., Koide, Y. et al., A novel integrin-linked kinase-binding protein, affixin, is involved in the early stage of cell-substrate interaction. J. Cell Biol. 2001, 153, 1251-1264.

[25] Hannigan, G. E., Leung-Hagesteijn, C., Fitz-Gibbon, L., Coppolino, M. G. et al., Regulation of cell adhesion and anchorage-dependent growth by a new beta 1-integrin-linked protein kinase. Nature 1996, 379, 9196. 
[26] Tu, Y., Huang, Y., Zhang, Y., Hua, Y., Wu, C., A new focal adhesion protein that interacts with integrinlinked kinase and regulates cell adhesion and spreading. J. Cell Biol. 2001, 153, 585-598.

[27] Tu, Y., Li, F., Goicoechea, S., Wu, C., The LIM-only protein PINCH directly interacts with integrin-linked kinase and is recruited to integrin-rich sites in spreading cells. Mol. Cell. Biol. 1999, 19, 2425-2434.

[28] Legate, K. R., Montanez, E., Kudlacek, O., Fassler, R., ILK, PINCH and parvin: the tIPP of integrin signalling. Nat. Rev. Mol. Cell Biol. 2006, 7, 20-31.

[29] Horton, E. R., Byron, A., Askari, J. A., Ng, D. H. et al., Definition of a consensus integrin adhesome and its dynamics during adhesion complex assembly and disassembly. Nat. Cell Biol. 2015, 17, 1577-1587.

[30] Geiger, B., Yamada, K. M., Molecular architecture and function of matrix adhesions. Cold Spring Harb Perspect. Biol. 2011, 3, 10.1101/cshperspect.a005033.

[31] Horton, E. R., Astudillo, P., Humphries, M. J., Humphries, J. D., Mechanosensitivity of integrin adhesion complexes: role of the consensus adhesome. Exp. Cell Res. 2016, 343, 7-13.

[32] Schiller, H. B., Fassler, R., Mechanosensitivity and compositional dynamics of cell-matrix adhesions. EMBO Rep. 2013, 14, 509-519.

[33] Rossier, O., Octeau, V., Sibarita, J. B., Leduc, C. et al., Integrins beta1 and beta3 exhibit distinct dynamic nanoscale organizations inside focal adhesions. Nat. Cell Biol. 2012, 14, 1057-1067.

[34] Zaidel-Bar, R., Cohen, M., Addadi, L., Geiger, B., Hierarchical assembly of cell-matrix adhesion complexes. Biochem. Soc. Trans. 2004, 32, 416-420.

[35] Rainero, E., Howe, J. D., Caswell, P. T., Jamieson, N. B. et al., Ligand-Occupied Integrin Internalization Links Nutrient Signaling to Invasive Migration. Cell. Rep. 2015, 10, 398-413.

[36] Roca-Cusachs, P., Gauthier, N. C., Del Rio, A., Sheetz, M. P., Clustering of alpha(5)beta(1) integrins determines adhesion strength whereas alpha(v)beta(3) and talin enable mechanotransduction. Proc. Natl. Acad. Sci. U. S. A. 2009, 106, 16245-16250.

[37] Elosegui-Artola, A., Oria, R., Chen, Y., Kosmalska, A. et al., Mechanical regulation of a molecular clutch defines force transmission and transduction in response to matrix rigidity. Nat. Cell Biol. 2016, 18, 540548. 
[38] Murphy, D. A., Courtneidge, S. A., The 'ins' and 'outs' of podosomes and invadopodia: characteristics, formation and function. Nat. Rev. Mol. Cell Biol. 2011, 12, 413-426.

[39] Cervero, P., Himmel, M., Kruger, M., Linder, S., Proteomic analysis of podosome fractions from macrophages reveals similarities to spreading initiation centres. Eur. J. Cell Biol. 2012, 91, 908-922.

[40] Havrylov, S., Park, M., MS/MS-based strategies for proteomic profiling of invasive cell structures. Proteomics 2015, 15, 272-286.

[41] Jia, Z., Barbier, L., Stuart, H., Amraei, M. et al., Tumor cell pseudopodial protrusions. Localized signaling domains coordinating cytoskeleton remodeling, cell adhesion, glycolysis, RNA translocation, and protein translation. J. Biol. Chem. 2005, 280, 30564-30573.

[42] Lin, Y. H., Park, Z. Y., Lin, D., Brahmbhatt, A. A. et al., Regulation of cell migration and survival by focal adhesion targeting of Lasp-1. J. Cell Biol. 2004, 165, 421-432.

[43] Fengos, G., Schmidt, A., Martin, K., Fluri, E. et al., Spatial proteomic and phospho-proteomic organization in three prototypical cell migration modes. Proteome Sci. 2014, 12, 23-5956-12-23.

[44] Choi, C. K., Vicente-Manzanares, M., Zareno, J., Whitmore, L. A. et al., Actin and alpha-actinin orchestrate the assembly and maturation of nascent adhesions in a myosin II motor-independent manner. Nat. Cell Biol. 2008, 10, 1039-1050.

[45] Alexandrova, A. Y., Arnold, K., Schaub, S., Vasiliev, J. M. et al., Comparative dynamics of retrograde actin flow and focal adhesions: formation of nascent adhesions triggers transition from fast to slow flow. PLoS One 2008,3 , e3234.

[46] Even-Ram, S., Doyle, A. D., Conti, M. A., Matsumoto, K. et al., Myosin IIA regulates cell motility and actomyosin-microtubule crosstalk. Nat. Cell Biol. 2007, 9, 299-309.

[47] Vicente-Manzanares, M., Zareno, J., Whitmore, L., Choi, C. K., Horwitz, A. F., Regulation of protrusion, adhesion dynamics, and polarity by myosins IIA and IIB in migrating cells. J. Cell Biol. 2007, 176, 573580.

[48] Arjonen, A., Alanko, J., Veltel, S., Ivaska, J., Distinct Recycling of Active and Inactive beta1 Integrins. Traffic $2012,13,610-625$. 
[49] Franco, S. J., Rodgers, M. A., Perrin, B. J., Han, J. et al., Calpain-mediated proteolysis of talin regulates adhesion dynamics. Nat. Cell Biol. 2004, 6, 977-983.

[50] Ezratty, E. J., Partridge, M. A., Gundersen, G. G., Microtubule-induced focal adhesion disassembly is mediated by dynamin and focal adhesion kinase. Nat. Cell Biol. 2005, 7, 581-590.

[51] Zaidel-Bar, R., Geiger, B., The switchable integrin adhesome. J. Cell. Sci. 2010, 123, 1385-1388.

[52] Geiger, T., Zaidel-Bar, R., Opening the floodgates: proteomics and the integrin adhesome. Curr. Opin. Cell Biol. 2012, 24, 562-568.

[53] Humphries, J. D., Byron, A., Bass, M. D., Craig, S. E. et al., Proteomic analysis of integrin-associated complexes identifies RCC2 as a dual regulator of Rac1 and Arf6. Sci. Signal. 2009, 2, ra51.

[54] Kuo, J. C., Han, X., Hsiao, C. T., Yates, J. R.,3rd, Waterman, C. M., Analysis of the myosin-II-responsive focal adhesion proteome reveals a role for beta-Pix in negative regulation of focal adhesion maturation. Nat. Cell Biol. 2011, 13, 383-393.

[55] Ng, D. H., Humphries, J. D., Byron, A., Millon-Fremillon, A., Humphries, M. J., Microtubule-dependent modulation of adhesion complex composition. PLoS One 2014, 9, e115213.

[56] Schiller, H. B., Hermann, M. R., Polleux, J., Vignaud, T. et al., beta1- and alphav-class integrins cooperate to regulate myosin II during rigidity sensing of fibronectin-based microenvironments. Nat. Cell Biol. $2013,15,625-636$.

[57] Schiller, H. B., Friedel, C. C., Boulegue, C., Fassler, R., Quantitative proteomics of the integrin adhesome show a myosin II-dependent recruitment of LIM domain proteins. EMBO Rep. 2011, 12, 259-266.

[58] Byron, A., Humphries, J. D., Craig, S. E., Knight, D., Humphries, M. J., Proteomic analysis of alpha4beta1 integrin adhesion complexes reveals alpha-subunit-dependent protein recruitment. Proteomics 2012, $12,2107-2114$.

[59] Kuo, J. C., Han, X., Yates, J. R.,3rd, Waterman, C. M., Isolation of focal adhesion proteins for biochemical and proteomic analysis. Methods Mol. Biol. 2012, 757, 297-323.

[60] Yue, J., Xie, M., Gou, X., Lee, P. et al., Microtubules regulate focal adhesion dynamics through MAP4K4. Dev. Cell. 2014, 31, 572-585. 
[61] Jones, M. C., Humphries, J. D., Byron, A., Millon-Fremillon, A. et al., Isolation of integrin-based adhesion complexes. Curr. Protoc. Cell. Biol. 2015, 66, 9.8.1-9.8.15.

[62] Robertson, J., Jacquemet, G., Byron, A., Jones, M. C. et al., Defining the phospho-adhesome through the phosphoproteomic analysis of integrin signalling. Nat. Commun. 2015, 6, 6265.

[63] Choi, H., Larsen, B., Lin, Z. Y., Breitkreutz, A. et al., SAINT: probabilistic scoring of affinity purificationmass spectrometry data. Nat. Methods 2011, 8, 70-73.

[64] Mellacheruvu, D., Wright, Z., Couzens, A. L., Lambert, J. P. et al., The CRAPome: a contaminant repository for affinity purification-mass spectrometry data. Nat. Methods 2013, 10, 730-736.

[65] Schuck, S., Honsho, M., Ekroos, K., Shevchenko, A., Simons, K., Resistance of cell membranes to different detergents. Proc. Natl. Acad. Sci. U. S. A. 2003, 100, 5795-5800.

[66] Seddon, A. M., Curnow, P., Booth, P. J., Membrane proteins, lipids and detergents: not just a soap opera. Biochim. Biophys. Acta 2004, 1666, 105-117.

[67] Harder, T., Kuhn, M., Immunoisolation of TCR signaling complexes from Jurkat T leukemic cells. Sci STKE 2001, 2001, L1.

[68] Roux, K. J., Kim, D. I., Raida, M., Burke, B., A promiscuous biotin ligase fusion protein identifies proximal and interacting proteins in mammalian cells. J. Cell Biol. 2012, 196, 801-810.

[69] Dong, J. M., Tay, F. P., Swa, H. L., Gunaratne, J. et al., Proximity biotinylation provides insight into the molecular composition of focal adhesions at the nanometer scale. Sci. Signal. 2016, 9, rs4.

[70] Dobreva, I., Fielding, A., Foster, L. J., Dedhar, S., Mapping the integrin-linked kinase interactome using SILAC. J. Proteome Res. 2008, 7, 1740-1749.

[71] Byron, A., Askari, J. A., Humphries, J. D., Jacquemet, G. et al., A proteomic approach reveals integrin activation state-dependent control of microtubule cortical targeting. Nat. Commun. 2015, 6, 6135.

[72] Kaverina, I., Krylyshkina, O., Small, J. V., Microtubule targeting of substrate contacts promotes their relaxation and dissociation. J. Cell Biol. 1999, 146, 1033-1044.

[73] Krylyshkina, O., Anderson, K. I., Kaverina, I., Upmann, I. et al., Nanometer targeting of microtubules to focal adhesions. J. Cell Biol. 2003, 161, 853-859. 
[74] Akhtar, N., Streuli, C. H., An integrin-ILK-microtubule network orients cell polarity and lumen formation in glandular epithelium. Nat. Cell Biol. 2013, 15, 17-27.

[75] Thery, M., Racine, V., Pepin, A., Piel, M. et al., The extracellular matrix guides the orientation of the cell division axis. Nat. Cell Biol. 2005, 7, 947-953.

[76] Myllymaki, S. M., Teravainen, T. P., Manninen, A., Two distinct integrin-mediated mechanisms contribute to apical lumen formation in epithelial cells. PLoS One 2011, 6, e19453.

[77] Moser, M., Legate, K. R., Zent, R., Fassler, R., The tail of integrins, talin, and kindlins. Science 2009, 324, 895-899.

[78] Roca-Cusachs, P., Iskratsch, T., Sheetz, M. P., Finding the weakest link: exploring integrin-mediated mechanical molecular pathways. J. Cell. Sci. 2012, 125, 3025-3038.

[79] Kong, F., Garcia, A. J., Mould, A. P., Humphries, M. J., Zhu, C., Demonstration of catch bonds between an integrin and its ligand. J. Cell Biol. 2009, 185, 1275-1284.

[80] Cai, Y., Biais, N., Giannone, G., Tanase, M. et al., Nonmuscle myosin IIA-dependent force inhibits cell spreading and drives F-actin flow. Biophys. J. 2006, 91, 3907-3920.

[81] Stricker, J., Beckham, Y., Davidson, M. W., Gardel, M. L., Myosin II-mediated focal adhesion maturation is tension insensitive. PLoS One 2013, 8, e70652.

[82] Li, A., Ponten, F., dos Remedios, C. G., The interactome of LIM domain proteins: the contributions of LIM domain proteins to heart failure and heart development. Proteomics 2012, 12, 203-225.

[83] Hirata, H., Tatsumi, H., Sokabe, M., Mechanical forces facilitate actin polymerization at focal adhesions in a zyxin-dependent manner. J. Cell. Sci. 2008, 121, 2795-2804.

[84] Knoll, R., Hoshijima, M., Hoffman, H. M., Person, V. et al., The cardiac mechanical stretch sensor machinery involves a $Z$ disc complex that is defective in a subset of human dilated cardiomyopathy. Cell $2002,111,943-955$.

[85] Stehbens, S., Wittmann, T., Targeting and transport: how microtubules control focal adhesion dynamics. J. Cell Biol. 2012, 198, 481-489. 
[86] Bershadsky, A., Chausovsky, A., Becker, E., Lyubimova, A., Geiger, B., Involvement of microtubules in the control of adhesion-dependent signal transduction. Curr. Biol. 1996, 6, 1279-1289.

[87] Kirchner, J., Kam, Z., Tzur, G., Bershadsky, A. D., Geiger, B., Live-cell monitoring of tyrosine phosphorylation in focal adhesions following microtubule disruption. J. Cell. Sci. 2003, 116, 975-986.

[88] Chang, Y. C., Nalbant, P., Birkenfeld, J., Chang, Z. F., Bokoch, G. M., GEF-H1 couples nocodazole-induced microtubule disassembly to cell contractility via RhoA. Mol. Biol. Cell 2008, 19, 2147-2153.

[89] Geiger, B., Spatz, J. P., Bershadsky, A. D., Environmental sensing through focal adhesions. Nat. Rev. Mol. Cell Biol. 2009, 10, 21-33.

[90] Teravainen, T. P., Myllymaki, S. M., Friedrichs, J., Strohmeyer, N. et al., alphaV-Integrins Are Required for Mechanotransduction in MDCK Epithelial Cells. PLoS One 2013, 8, e71485.

[91] Elosegui-Artola, A., Bazellieres, E., Allen, M. D., Andreu, I. et al., Rigidity sensing and adaptation through regulation of integrin types. Nat. Mater. 2014, 13, 631-637.

[92] Kanchanawong, P., Shtengel, G., Pasapera, A. M., Ramko, E. B. et al., Nanoscale architecture of integrinbased cell adhesions. Nature $2010,468,580-584$

[93] Greciano, P. G., Moyano, J. V., Buschmann, M. M., Tang, J. et al., Laminin 511 partners with laminin 332 to mediate directional migration of Madin-Darby canine kidney epithelial cells. Mol. Biol. Cell 2012, 23, $121-136$

[94] Serrels, B., Frame, M. C., FAK and talin: who is taking whom to the integrin engagement party? J. Cell Biol. 2012, 196, 185-187.

[95] Horton, E. R., Humphries, J. D., Stutchbury, B., Jacquemet, G. et al., Modulation of FAK and Src adhesion signaling occurs independently of adhesion complex composition. J. Cell Biol. 2016, 212, 349-364.

[96] Scott, J. D., Pawson, T., Cell signaling in space and time: where proteins come together and when they're apart. Science 2009, 326, 1220-1224.

[97] Zhang, Y., Chen, K., Tu, Y., Velyvis, A. et al., Assembly of the PINCH-ILK-CH-ILKBP complex precedes and is essential for localization of each component to cell-matrix adhesion sites. J. Cell. Sci. 2002, 115, 4777 4786. 
[98] Pawson, T., Scott, J. D., Protein phosphorylation in signaling--50 years and counting. Trends Biochem. Sci. 2005, 30, 286-290.

[99] Mitra, S. K., Schlaepfer, D. D., Integrin-regulated FAK-Src signaling in normal and cancer cells. Curr. Opin. Cell Biol. 2006, 18, 516-523.

[100] Harburger, D. S., Calderwood, D. A., Integrin signalling at a glance. J. Cell. Sci. 2009, 122, 159-163.

[101] Larsen, M., Tremblay, M. L., Yamada, K. M., Phosphatases in cell-matrix adhesion and migration. Nat. Rev. Mol. Cell Biol. 2003, 4, 700-711.

[102] Chen, Y., Lu, B., Yang, Q., Fearns, C. et al., Combined integrin phosphoproteomic analyses and small interfering RNA-based functional screening identify key regulators for cancer cell adhesion and migration. Cancer Res. 2009, 69, 3713-3720.

[103] Ivaska, J., Heino, J., Cooperation Between Integrins and Growth Factor Receptors in Signaling and Endocytosis. Annu. Rev. Cell Dev. Biol. 2011, 27, 291-320.

[104] Margadant, C., Sonnenberg, A., Integrin-TGF-beta crosstalk in fibrosis, cancer and wound healing. EMBO Rep. 2010, 11, 97-105.

[105] Wickstrom, S. A., Fassler, R., Regulation of membrane traffic by integrin signaling. Trends Cell Biol. 2011, $21,266-273$.

[106] Byron, A., Frame, M. C., Adhesion protein networks reveal functions proximal and distal to cell-matrix contacts. Curr. Opin. Cell Biol. 2016, 39, 93-100.

[107] Humphries, J. D., Paul, N. R., Humphries, M. J., Morgan, M. R., Emerging properties of adhesion complexes: what are they and what do they do? Trends Cell Biol. 2015, 25, 388-397.

[108] Yurchenco, P. D., Basement membranes: cell scaffoldings and signaling platforms. Cold Spring Harb Perspect. Biol. 2011, 3, 10.1101/cshperspect.a004911.

[109] Hohenester, E., Yurchenco, P. D., Laminins in basement membrane assembly. Cell. Adh Migr. 2013, 7, $56-63$

[110] Manninen, A., Epithelial polarity - Generating and integrating signals from the ECM with integrins. Exp. Cell Res. 2015, 334, 337-349. 
[111] Zhang, H., Labouesse, M., The making of hemidesmosome structures in vivo. Dev. Dyn. 2010, 239, 14651476.

[112] Uematsu, J., Nishizawa, Y., Sonnenberg, A., Owaribe, K., Demonstration of type II hemidesmosomes in a mammary gland epithelial cell line, BMGE-H. J. Biochem. 1994, 115, 469-476.

[113] Rezniczek, G. A., de Pereda, J. M., Reipert, S., Wiche, G., Linking integrin alpha6beta4-based cell adhesion to the intermediate filament cytoskeleton: direct interaction between the beta4 subunit and plectin at multiple molecular sites. J. Cell Biol. 1998, 141, 209-225.

[114] Lynch, C. D., Lazar, A. M., Iskratsch, T., Zhang, X., Sheetz, M. P., Endoplasmic spreading requires coalescence of vimentin intermediate filaments at force-bearing adhesions. Mol. Biol. Cell 2013, 24, 2130.

[115] Carter, W. G., Kaur, P., Gil, S. G., Gahr, P. J., Wayner, E. A., Distinct functions for integrins alpha 3 beta 1 in focal adhesions and alpha 6 beta 4/bullous pemphigoid antigen in a new stable anchoring contact (SAC) of keratinocytes: relation to hemidesmosomes. J. Cell Biol. 1990, 111, 3141-3154.

[116] Gavin, A. C., Aloy, P., Grandi, P., Krause, R. et al., Proteome survey reveals modularity of the yeast cell machinery. Nature 2006, 440, 631-636.

[117] Wepf, A., Glatter, T., Schmidt, A., Aebersold, R., Gstaiger, M., Quantitative interaction proteomics using mass spectrometry. Nat. Methods 2009, 6, 203-205.

[118] Schmidt, C., Lenz, C., Grote, M., Luhrmann, R., Urlaub, H., Determination of protein stoichiometry within protein complexes using absolute quantification and multiple reaction monitoring. Anal. Chem. $2010,82,2784-2796$.

[119] Gloeckner, C. J., Boldt, K., Schumacher, A., Roepman, R., Ueffing, M., A novel tandem affinity purification strategy for the efficient isolation and characterisation of native protein complexes. Proteomics 2007, 7, 4228-4234.

[120] Rigaut, G., Shevchenko, A., Rutz, B., Wilm, M. et al., A generic protein purification method for protein complex characterization and proteome exploration. Nat. Biotechnol. 1999, 17, 1030-1032. 
[121] Burckstummer, T., Bennett, K. L., Preradovic, A., Schutze, G. et al., An efficient tandem affinity purification procedure for interaction proteomics in mammalian cells. Nat. Methods 2006, 3, 10131019.

[122] Glatter, T., Wepf, A., Aebersold, R., Gstaiger, M., An integrated workflow for charting the human interaction proteome: insights into the PP2A system. Mol. Syst. Biol. 2009, 5, 237.

[123] Varjosalo, M., Sacco, R., Stukalov, A., van Drogen, A. et al., Interlaboratory reproducibility of large-scale human protein-complex analysis by standardized AP-MS. Nat. Methods 2013, 10, 307-314.

[124] Roux, K. J., Kim, D. I., Burke, B., BiolD: a screen for protein-protein interactions. Curr. Protoc. Protein Sci. $2013,74,19.23 .1-19.23 .14$

[125] Franceschini, A., Szklarczyk, D., Frankild, S., Kuhn, M. et al., STRING v9.1: protein-protein interaction networks, with increased coverage and integration. Nucleic Acids Res. 2013, 41, D808-815.

[126] Supek, F., Bosnjak, M., Skunca, N., Smuc, T., REVIGO summarizes and visualizes long lists of gene ontology terms. PLoS One 2011, 6, e21800.

[127] Huang, I. H., Hsiao, C. T., Wu, J. C., Shen, R. F. et al., GEF-H1 controls focal adhesion signaling that regulates mesenchymal stem cell lineage commitment. J. Cell. Sci. 2014, 127, 4186-4200.

[128] Ajeian, J. N., Horton, E. R., Astudillo, P., Byron, A. et al., Proteomic analysis of integrin-associated complexes from mesenchymal stem cells. Proteomics Clin. Appl. 2016, 10, 51-57. 


\section{Figure legends}

Figure 1. Integrin activation and formation of integrin adhesion complexes

A) Inactive integrins exist in bent conformation in which the C-termini of $\alpha$ - and $\beta$-subunits are in close apposition. Upon activation integrins adopt an extended conformation where extracellular domains stand up perpendicular to the plasma membrane and transmembrane domains separate allowing binding of intracellular effectors to the C-terminal cytoplasmic tails. These conformational changes also extend to the ligand-binding domain of integrins such that the ligand-binding pocket is exposed (closed-to-open transition; not shown) [5-7]. The active conformation can be promoted by binding of cytoplasmic activator proteins such as talins and kindlins (red ovals) to specific motifs on the cytoplasmic tails of integrins (inside-out signaling). Alternatively, binding of extracellular ligands to integrin heterodimer may stabilize active integrin conformation thereby facilitating assembly of cytoplasmic effectors (outside-in signaling). Note that integrin inhibitors (blue ovals) also bind to the cytoplasmic integrin tails and promote inactive conformation [4].

B) Activated integrins engage with the ECM and recruit cytoplasmic effectors such as talin (TLN) to form small nascent adhesions that link to the actin cytoskeleton. In conjunction with increasing forces exerted on molecules at nascent adhesions integrins cluster into larger foci to form focal adhesions that are not only bigger but contain a large number of additional components such as vinculin $(\mathrm{VCL})$ to strengthen the actin linkage [31, 32]. Mechanical forces that regulate the maturation of focal adhesions are generated by polymerizing actin fibers and by non-muscle myosin II (NMMII)-driven actomyosin contractility. 
C) An illustration of the complexity of protein-protein interaction networks at integrin adhesion complexes (IACs). The graph shows a STRING analysis [125] of the most frequently identified IAC components. Only proteins that are found in at least two of the three databases (literaturecurated adhesome, core consensus adhesome and paxillin/kindlin-2 BiolD interactome; see 2A) were included in the analysis. Red lines indicate experimentally determined interactions and blue lines depict pairwise interactions from curated databases. Proteins found in all three databases are shown in bold. Proteins listed in the Kyoto Encyclopedia of Genes and Genomes (KEGG) focal adhesion pathway are shown as red circles.

\section{Figure 2. Comparison of literature-curated and MS-derived adhesomes}

A) Venn diagram illustrating the comparison of IAC compositions determined by three independent methods: literature-curated adhesome [2], biochemical IAC isolation-based core consensus adhesome [29] and BiolD proximity biotin ligation-based combined interactome of paxillin (PXN) and kindlin-2 (FERMT2) [69].

B) Gene Ontology treemaps constructed with REVIGO [126] for cellular components of the literature-curated adhesome, C) core consensus adhesome and D) BiolD-based combined interactome of paxillin and kindlin-2 (PXN + FERMT2 BioID).

Figure 3. Schemes of commonly used methods to isolate IACs.

A) Isolation of IACs by first coating paramagnetic beads with integrin ligand. Non-specific binding sites are then blocked on the beads and cells are incubated together with the beads followed by 
addition of chemical cross-linker(s). Cross-linkers are quenched and cells lysed using detergents and sonication. Bead-bound IACs are washed and finally eluted for MS analysis [53, 61].

B) Isolation of IACs by seeding cells on ligand-coated substrate followed by hypotonic lysis and removal of cell bodies by hydrodynamic force. The protocol also includes removal of excess actin and fibronectin (ligand) by immuno-depletion prior to MS analysis [59].

C) Isolation of IACs by seeding cell onto ligand-coated substrate followed by addition of chemical cross-linker(s) to preserve low-affinity interactions. Cells are then lysed using detergents and cell bodies removed by hydrodynamic force (or sonication) [57, 61].

D) Characterization of proteins interacting with selected FA-components. Dong et al. fused BirAdomain to Paxillin or Kindlin-2 [69]. Cells were transfected with either BirA-paxillin or BirAKindlin-2. Upon addition of biotin BirA fused to selected protein generates a reactive biotinoyl5'-AMP that forms a covalent bond with primary amine groups within a radius of 15 - to $20 \mathrm{~nm}$ thus effectively labeling BirA fusion protein interaction partners (depicted as circles with red borderline in the scheme) [124]. Cells are then lysed using detergents, lysates sonicated and biotinylated proteins captured for MS analysis using biotin affinity capture (for example NeutrAvidin-beads) [69].

Figure 4. Gene Ontology treemap of the meta-adhesome

Gene Ontology treemap constructed with REVIGO for components of the meta-adhesome [29]. Meta-adhesome represents components of IACs on FN ligand and combines several published quantitative proteomic datasets $[29,53,55-57,62]$. 
A

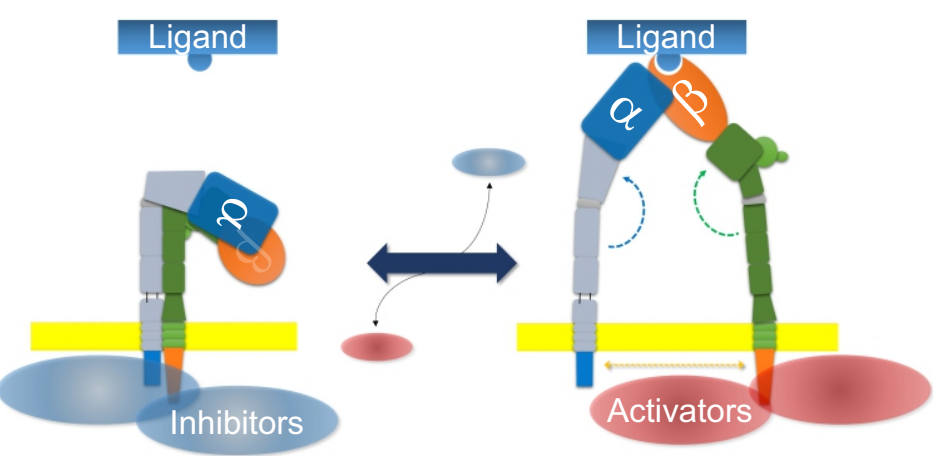

B

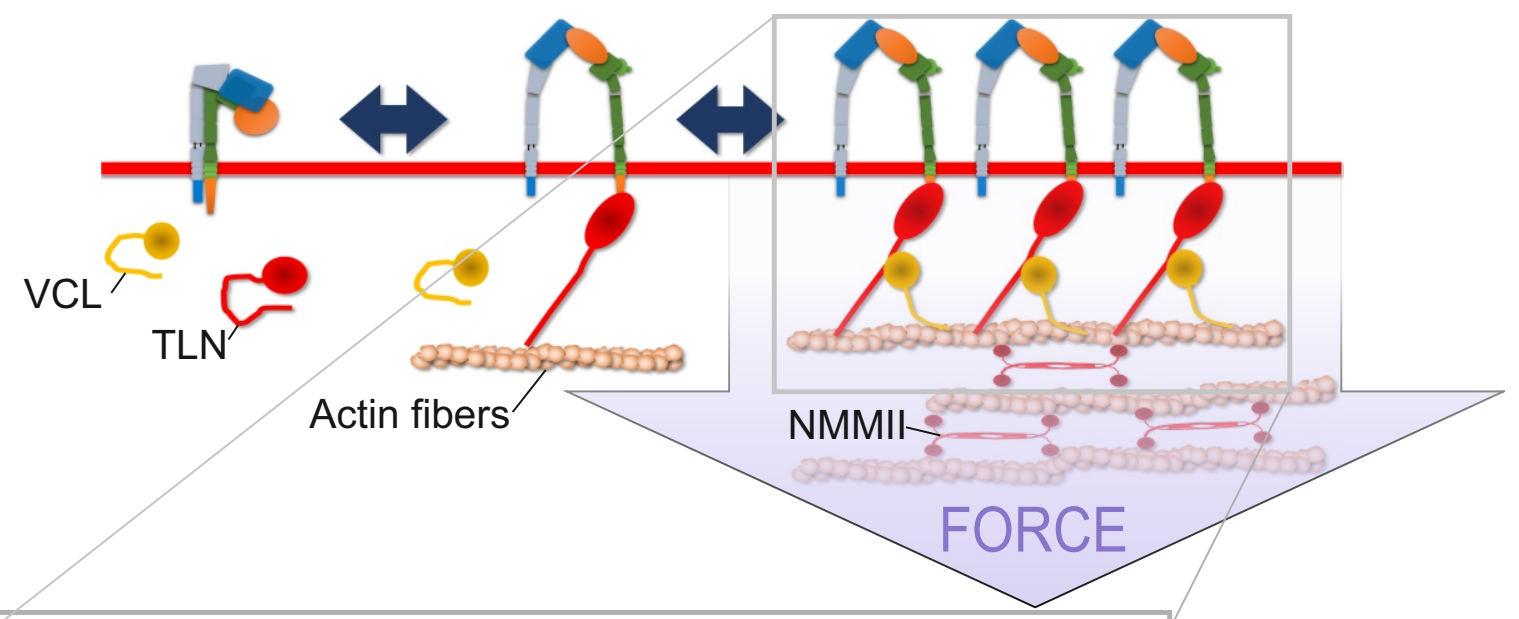

C
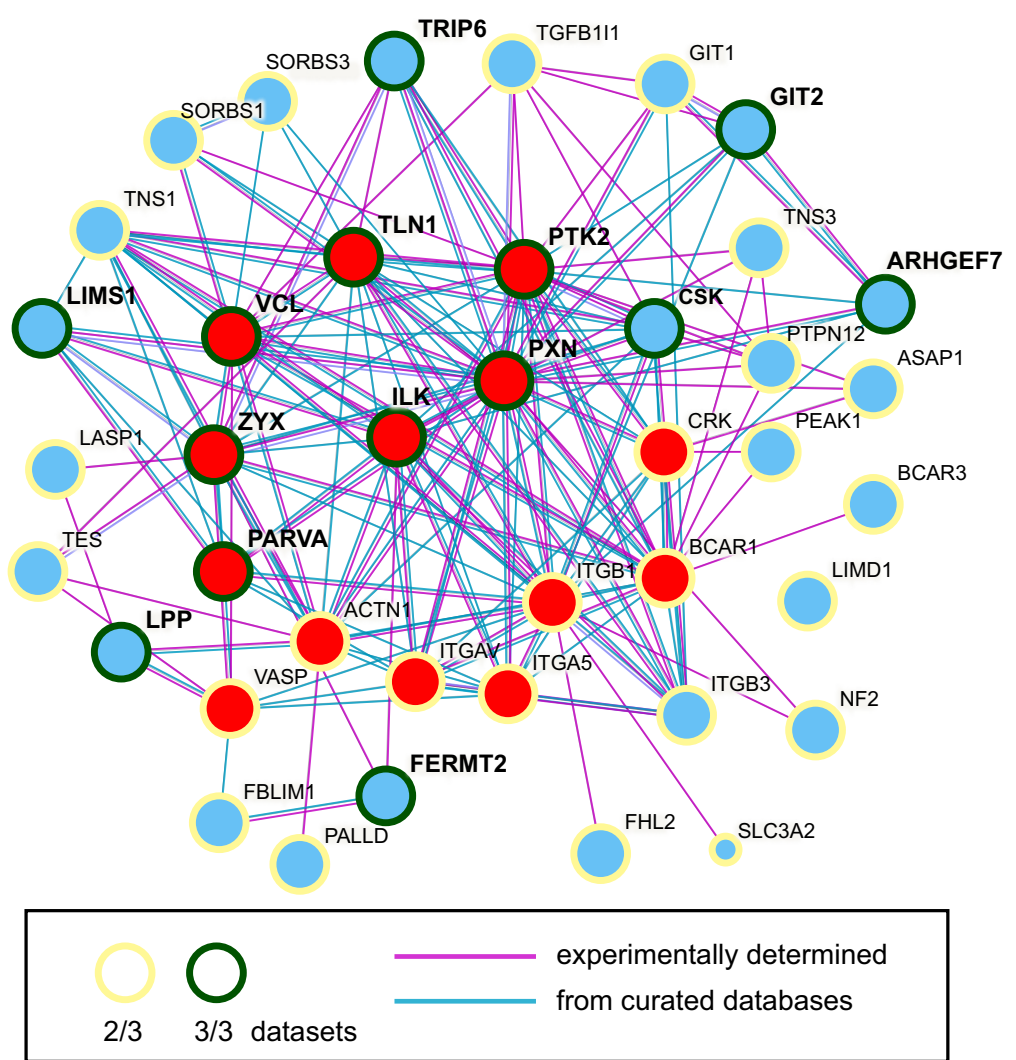
A

Literature-curated

adhesome (232)

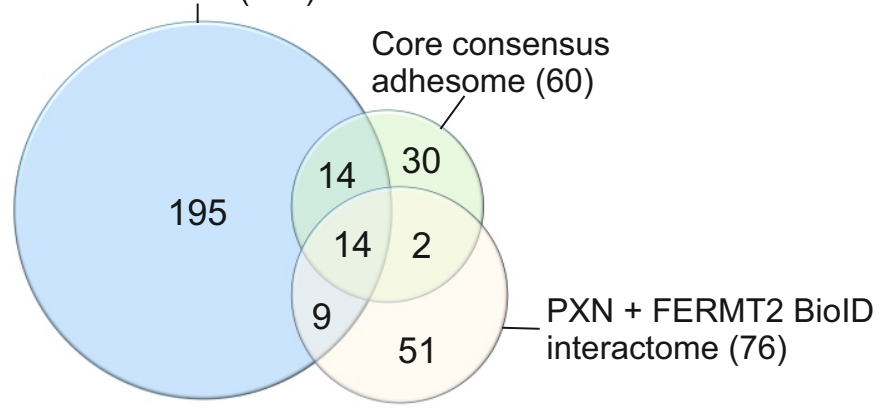

B

Literature-curated adhesome

\begin{tabular}{|c|c|c|c|c|c|c|c|}
\hline \multirow{2}{*}{\multicolumn{2}{|c|}{$\begin{array}{l}\text { plasma membrane } \\
\text { plasma membrane part }\end{array}$}} & \multirow{3}{*}{ 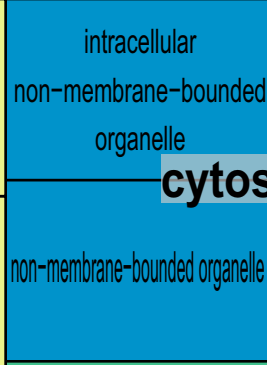 } & \multicolumn{2}{|c|}{ cytoskeleton } & \multicolumn{3}{|c|}{$\begin{array}{l}\text { lamellipodium provelition } \\
\text {-lamellipodiuar } \\
\text { neuron projection }\end{array}$} \\
\hline & & & \multicolumn{2}{|r|}{ nart. } & \multicolumn{2}{|c|}{ cell projection } & (Obsoletele) cell fraction \\
\hline \multirow[t]{2}{*}{ lasma membrane part } & \multirow{2}{*}{ 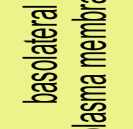 } & & & & \multirow{2}{*}{$\begin{array}{l}\text { (obsolete) } \\
\text { insoluble fraction }\end{array}$} & & \multirow{2}{*}{$\begin{array}{l}\text { Possolete } \\
\text { menbrantraction }\end{array}$} \\
\hline & & & & & & & \\
\hline & & & & unction & & & synaps \\
\hline asma membrane cytop & & & ortex| है & & receptor complex & & \\
\hline
\end{tabular}

C

Core consensus adhesome

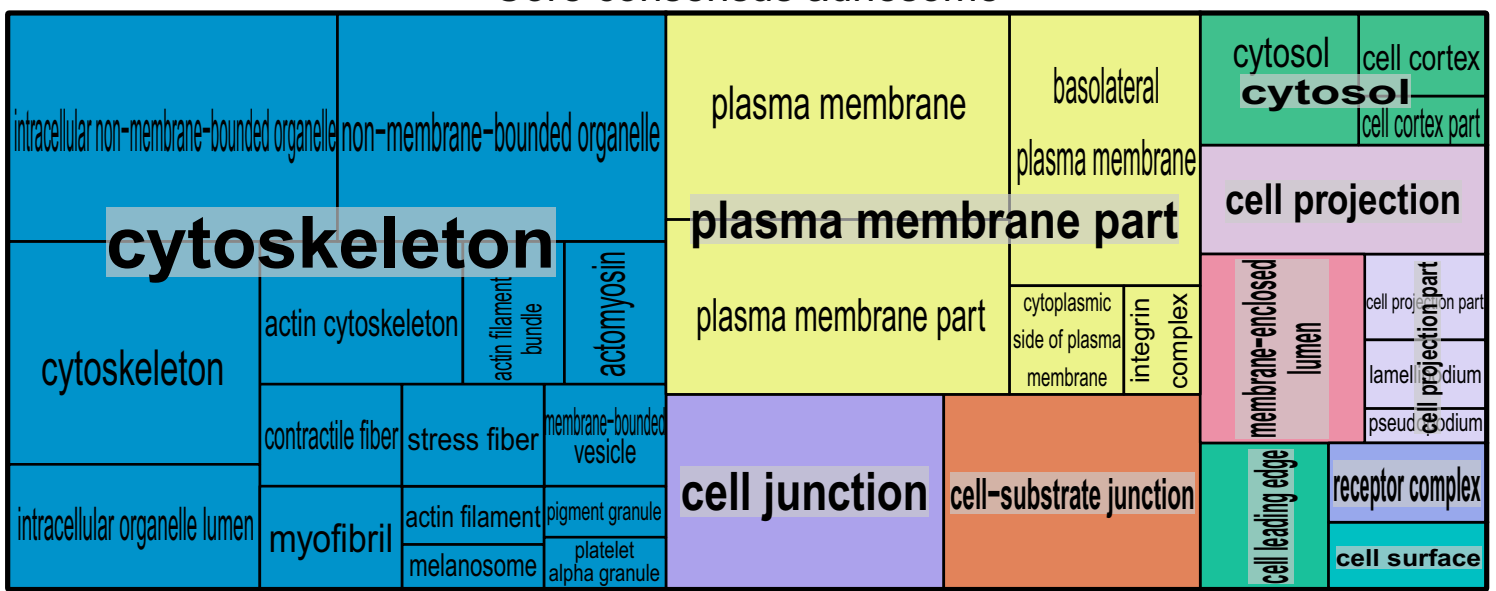

D

PXN + FERMT2 BiolD

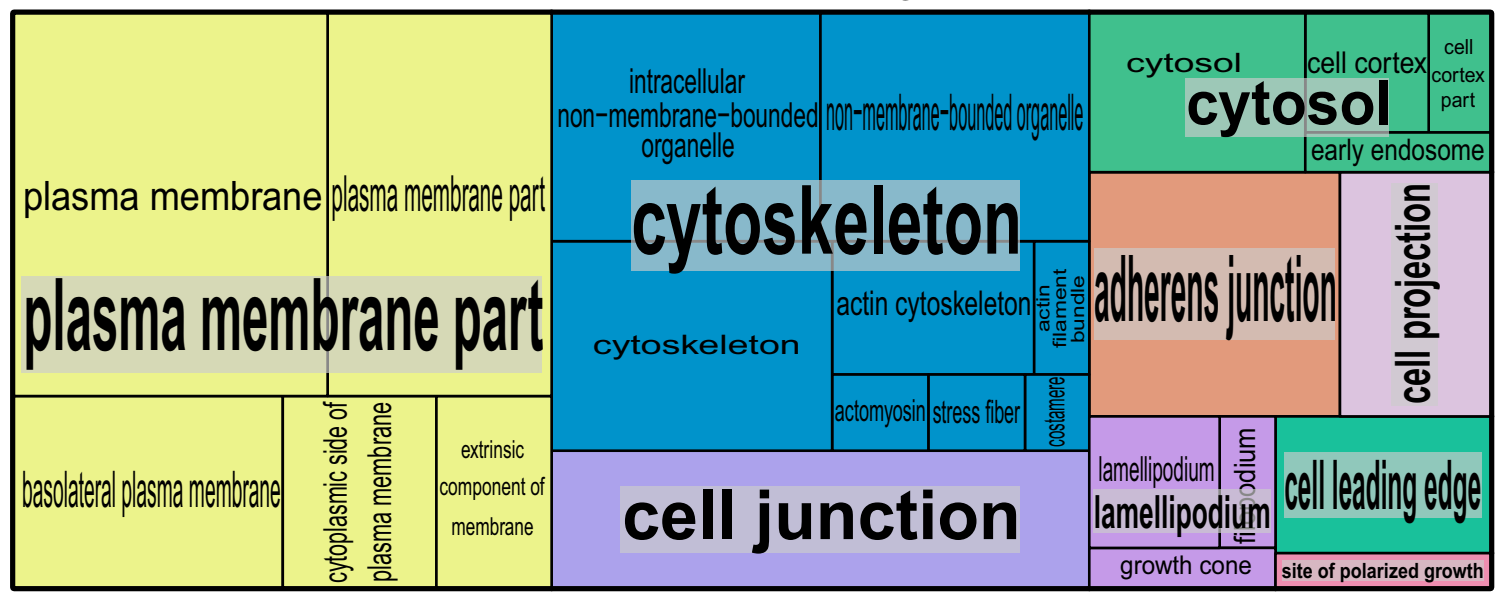

Figure 2. 
A

Paramagnetic beads coated with ligand

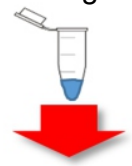

Cells incubated with the beads followed by chemical crosslinking

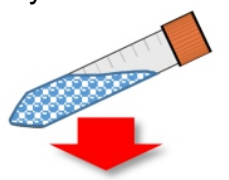

Crosslinker quenched and cells lysed using detergent or sonication

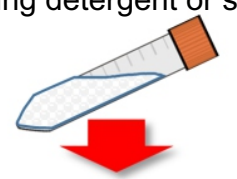

IACs harvested and eluted for MS analysis

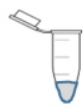

C
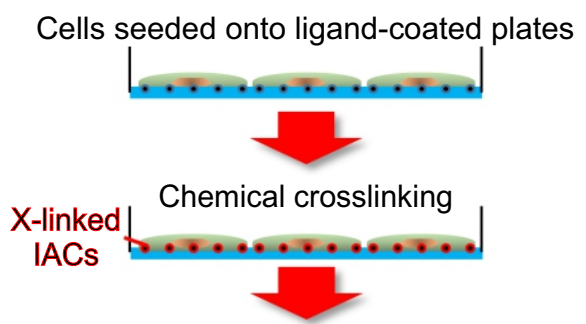

Crosslinker quenched and cells lysed with detergent

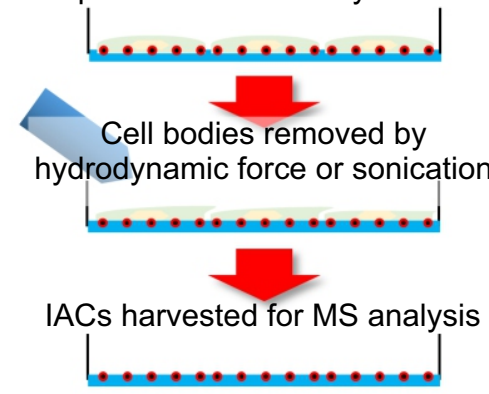

B

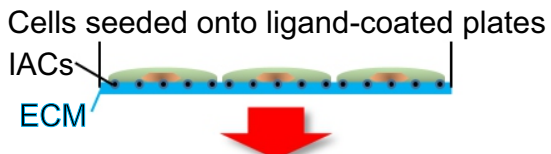

Cells allowed to swell in low ionic strength buffer

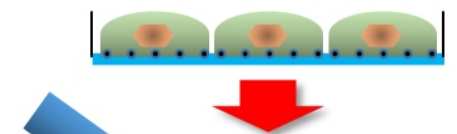

Cell bodies removed by hydrodynamic force

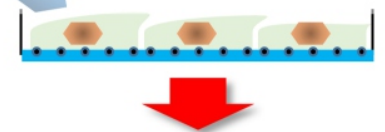

IACs harvested for MS analysis

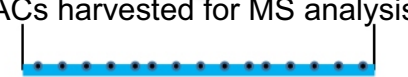

D

Expression of selected BirA-fusion protein in cells

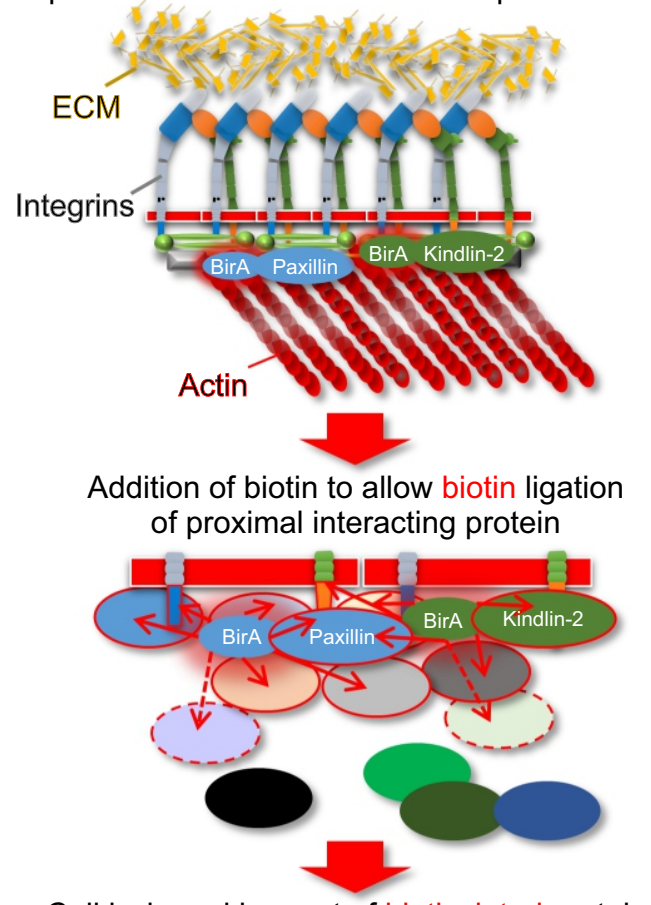

Cell lysis and harvest of biotinylated proteins

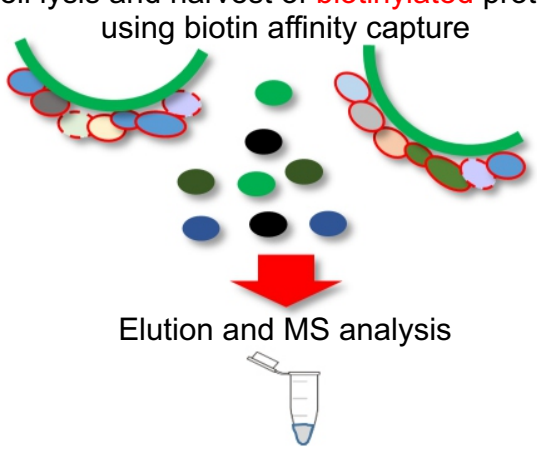




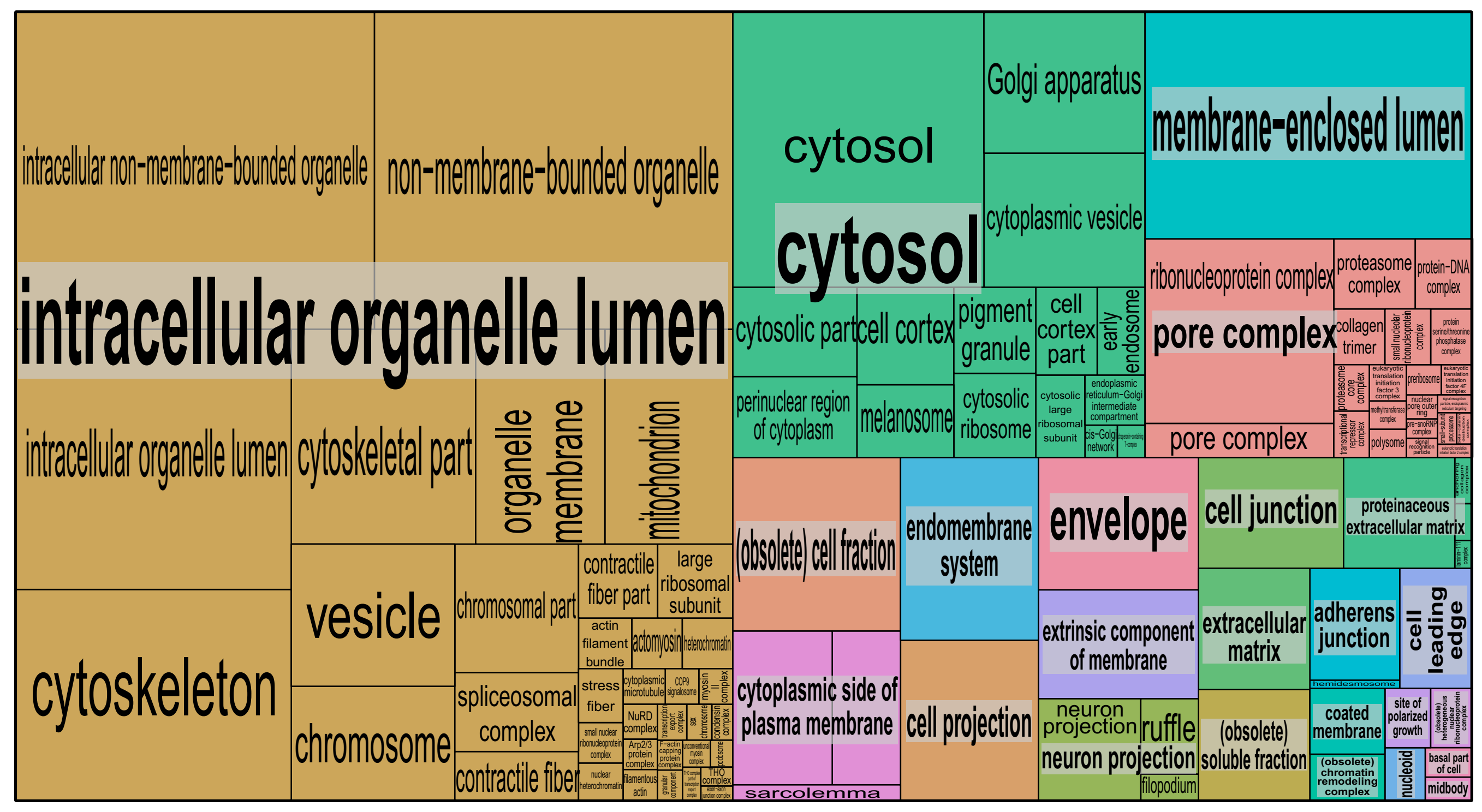

Figure 4. 